\title{
Meta-Cognitive Strategies and Nursing Students' Achievement
}

\author{
1, 2*Salari M., ${ }^{2}$ Rohaniahmad tarmizi, ${ }^{2}$ Ramlah Hamzah, ${ }^{2}$ Zarida Hambali \\ ${ }^{1}$ Yasuj University of Medical Sciences, Yasuj, Iran \\ 2Universiti Putra Malaysia, Selangor, Malaysia \\ *salarimo@yahoo.com
}

\begin{abstract}
In the information era in which there is an increasing and rapid information change, education system needs to enable students to solve the problems of real world with their acquired skills. Metacognition is essential for successful learning and students can learn and use it to improve their performance. This paper was an attempt to investigate the reliability of meta-cognitive awareness inventory that is generated by Schraw and Dennison (1994) and its correlation with nursing students' achievement in Iran. The design adopted for this study was a descriptive correlation design. To this end, 40 female university students majoring in nursing were selected as the sample. Pediatric nursing performance was measured using a test which included higher and lower order questions. The results indicated that (a) the questionnaire has acceptable internal consistency, with a Cronbach alpha coefficient of .74 , (b) there was a strong, positive correlation between the two variables, $r=.729, n=40, p<0.01$, with high levels of meta-cognitive awareness associated with higher levels of performance in course of pediatric nursing. In conclusion, meta-cognitive strategies may have impact on nursing performance among university students.
\end{abstract}

Keywords: Achievement; Nursing Students; Meta-cognitive Awareness

\section{Introduction and Previous Studies}

The world today needs graduates who can take advantage of their diverse skills and in-depth academic knowledge in order to benefit from professional problem solving and long life learning. Hence, nurses encountering fast changes in the system of health care and education systems will realize that they are in a challenging and continually varying complex situations. Therefore, education should be related and accommodated to the future profession and offers learning opportunities that correspond with curriculum to be successful (Bastable, 2007; Bengtsson \& Ohlsson, 2010; Gillespie \& McFetridge, 2006). The teaching strategies should enable the learners to cope with these challenges. Unfortunately enough, the traditional strategies have been proved unable to accomplish such an importance. In new approaches, however, the instructors encourage the learners to promote motivation, high thinking skills, lifelong learning, problem solving, group process skills, creativity, and empowerment. Learners are not passive in this approach. Rather, they are often active in learning. Students, in addition, need to continually evaluate how the learning helps them expand their understanding. They will become skilful learners in the constructivist classroom by questioning themselves and their strategies. Such a process provides them with extensive tools to maintain learning and will make them perceive things in new ways (Moore, 2005).

Schraw and Dennison (1994, p. 460) define metacognition as "the ability to reflect upon, understand, and control one's learning". Generally speaking, metacognition refers not only to the learner's knowledge about his cognitive processes but also his ability to actively and effectively control these processes (Flavell, 1976). Metacognition has two major components, including knowledge about cognition and executive processes or regulation of cognition (Pintrich, 2002). Instead of using person, task and strategy variables by Flavell (Flavell, 1979), Schraw and Moshman (1995) subdivided metacognitive knowledge and regulation of cognition with different labelling. Metacognitive regulations determine a person's ability and activities that help control one's thinking or learning of information relevant to the goal. It has five component skills that are: planning, information management strategies, comprehension monitoring, debugging strategies, and evaluation. Planning, monitoring, and evaluation are essential and included in all accounts. By planning, one can select suitable strategies and allocate resources that affect performance. Monitoring enhances with training and practice by awareness of comprehension and task performance. Evaluation involves assessing the products and the regulatory process of one's learning. (e.g., asking questions and re-evaluating one's goals and conclusions. In sum, regulatory skill enhances performance by "better use of cognitive resources such as attention, better use of strategies, and a greater 
awareness of comprehension breakdowns" (Gregory Schraw \& Dennison, 1994; Gregory Schraw \& Moshman, 1995, p. 355).

According to Pintrich (2002), metacognitive knowledge refers to being aware of and having knowledge about one's own cognition. Metacognitive knowledge has three sub-processes that facilitate the reflective aspect of metacognition: declarative knowledge, procedural knowledge, and conditional knowledge (Gregory Schraw \& Dennison, 1994; Gregory Schraw \& Moshman, 1995). Declarative knowledge is knowledge about oneself as a learner and one's preferred strategies for performing tasks. Procedural knowledge is knowledge about how to use metacognitive strategies (setting sub-goals, asking oneself questions, and rereading) and general learning strategies (summarizing, outlining, and concept mapping) to improve problem solving performance. Conditional knowledge is an aspect of knowledge that enables the learner to know when and why to use certain strategies. Research has shown that skilful learners make use of conditional knowledge to improve their knowledge (Pintrich, 2002; Gregory Schraw \& Dennison, 1994; Gregory Schraw \& Moshman, 1995). It has been shown that cognitively aware learners stand in a more privileged position than unaware learners to plan, sequence, and monitor their learning (Pressley \& Ghatala, 1990; Gregory Schraw \& Dennison, 1994; Swanson, 1990). In addition, there was a significant positive relationship between metacognitive strategies with problem-solving performance and educational progress of students in different courses (Abdolhossini, 2012; Babakhani, 2011; Bayat \& Tarmizi, 2010; Goh \& Hu, 2013).

In this research, the researcher will use a valid and reliable $(>0.88)$ inventory that was developed and put to the test by Schraw and Dennison (1994) to identify the learners that were meta-cognitively aware in a quick and reliable way. This inventory (MAI) includes 52 items that are self-report and entail eight component processes falling under knowledge and regulation of cognition that are reciprocally correlated and at the same time compensatory (Gregory Schraw \& Dennison, 1994). Nowadays, "the instructional implications urge researchers to research the impact of instructional strategies that focus upon the incorporation of metacognitive awareness" (Valcke, 2002, p. 150). Four general approaches improve meta-cognition in the classroom. These include enhancing construction of new knowledge, promoting knowledge of cognition, improving a monitoring exploratory, and fostering a supportive motivational environment (G. Schraw, 1998).The issue is how the MAI is related to performance when engaged in welldefined and ill-defined tasks. It would appear that metacognitive awareness may play a much better role in the performance of complex or ill-structured tasks (Gregory Schraw \& Dennison, 1994). In summary, metacognition is necessary for effective learning because it helps learners to better take control of their cognitive skills, and to identify the weak points that can be strengthened through building new cognitive skills (Babakhani, 2011; Gwee, 2009). A variety of instructional practices like interactive approach that blends direct instruction, teacher and expert learner modelling, reflection on the part of students and group activities that enable learners to share with others their cognitive knowledge enhance metacognitive awareness. Students can learn and use metacognitive knowledge and regulation to improve their performance(G. Schraw, 1998). This paper was an attempt to investigate the reliability of meta-cognitive awareness inventory that is generated by Schraw and Dennison (1994) and its correlation with nursing student achievement in Iran.

\section{Methodology}

This study adopted a descriptive correlation design that was used to determine the possible effects of metacognitive strategies of the learners on the pediatric nursing performance after a lecture-based strategy. A self-report instrument was employed to evaluate metacognitive strategy. The pediatric nursing performance was an achievement test consisting of higher and lower order questions and total scores gained for the course. The subjects were chosen from the third year students who took pediatric nursing course in one of the branches of the Azad University in Iran. The Pediatric Nursing Achievement Test (PNAT) had multiple-choice and open-ended items. The PNAT comprised of 22 multiple-choice and 22 open-ended items based on the subtopic of Pediatric Nursing topics. There was no time limitation to answer the questions because the researcher wanted all the questions to be answered by all the students. It was considered one mark for each correct answer of multiple-choice and three marks for open-ended questions. So, the overall performance test for the PNAT was ranged between 0 and 88 .

In addition, the students' answers were classified by the researcher as acquisition of either high order (cognitive domain) or low order (cognitive domain) performance. The high order cognitive domain performance refers to the students' ability to analyze, synthesize, and evaluate the pediatric nursing 
problems, while the low order cognitive domain performance refers to the students' ability to process the pediatric nursing problems which need knowledge, comprehension, and application based on the Bloom's Taxonomy. Hence, the total scores for high and low order cognitive domains were 66 and 22, respectively. The MAI was used to measure the students' general metacognitive awareness as they were processing pediatric nursing problems. The MAI was adapted from Schraw and Dennison (1994) to measure the students' metacognitive awareness. This instrument includes 52 items and needs to be replied based on five-point Likert scale. The students needed to show ability to reflect, know, understand, and control their learning by different strategies while working on questions or problems by circling the proper scale where scale 1 indicates "almost never or never" occur, scale 2 indicates "only occasionally or rarely", scale 3 indicates "sometimes", scale 4 indicates "usually or often", and scale 5 indicates "almost always or always". There were two main metacognitive subscales including knowledge of cognition and regulation of cognition during nursing problem solving. Knowledge of cognition also had three minor subscales (sub processes) that facilitate the reflective feature of metacognition: declarative knowledge, procedural knowledge, and conditional knowledge. Regulation of cognition included five minor subscales (sub processes or subcomponents) that facilitated the control aspect of learning including planning, information management strategies, comprehension monitoring, debugging strategies, and evaluation.

Examples of items of the MAI based on the eight sub scales were as follows. Declarative knowledge: "When I process nursing problems, I understand my intellectual strengths and weaknesses"; Procedural knowledge: "I am aware of what strategies I use when I process nursing problems"; Conditional knowledge: "I learn best when I know something related to the new nursing (topics) concepts"; Planning: "I think about what I really need to know before I begin processing health and nursing problems (nursing procedures)"; Information management strategies: "When I process nursing problem, I focus on the meaning and significance of new information of the problem"; Monitoring: "I consider several alternatives to processing nursing problems before I answer"; Debugging strategies: "When I process nursing problems, I stop and review (go) back over new information of problem that is not clear"; Evaluation: "I ask myself how well I accomplished my goals once I'm finished nursing problem". Score for each subscale might have ranged from 4 to 50 while the overall metacognitive awareness scale might have ranged from 52 to 260. Since, the instrument was in the English (source) Language; it was translated into Persian (target) Language by a translator. Then the Persian Language version was translated back into the English Language by another translator. Through this, two source language versions were compared to ensure a truthful translation and to provide additional evidence of quality, that is, back-translation (Maneesriwongul \& Dixon, 2004). For content validation, the instrument was submitted to three nursing lecturers. Table 1 shows the items distribution for each subscale.

\begin{tabular}{lcc}
\multicolumn{4}{l}{ Table 1: Metacognitive awareness items' distribution according to minor subscales } \\
\hline Subscale & Item Number & Total Items \\
\hline Declarative Knowledge & $5,10,12,16,17,20,32,46$ & 8 \\
Procedural Knowledge & $3,14,27,33$ & 4 \\
Conditional Knowledge & $15,18,26,29,35$ & 5 \\
Planning & $4,6,8,22,23,42,45$ & 7 \\
Information Management Strategies & $9,13,30,31,37,39,41,43,47,48$ & 10 \\
Monitoring & $1,2,11,21,28,34,49$ & 7 \\
Debugging Strategies & $25,40,44,51,52$ & 5 \\
Evaluation & $7,19,24,36,38,50$ & 6 \\
\hline
\end{tabular}

\section{Findings}

A total of 40 sets of questionnaire and test were collected. The respondents' major was nursing.

Cronbach's alpha for the Persian version of Metacognitive Awareness Inventory: Internal consistency reliability was determined by Cronbach alpha. To this end, an attempt was made to determine how the items on a test were related to those of the other test and to the test as a whole. The tests are internally consistent if both of them really measure similar abilities. If items can have more than two scores (e.g., 0 , $1,2,3,4)$, then Cronbach's alpha should be used. Subjects are ensured to respond to a question on a scale of varying degrees of intensity between two extremes through a Likert scale format. A tool has an acceptable level of reliability and is, therefore, reliable if it has a level of 0.70 or higher (Gay, Mills, \& Airasian, 2006; LoBiondo-Wood \& Haber, 2006). In order to test the questionnaire for its internal consistency, we calculated Cronbach's alpha for the Persian version. The overall reliability coefficient for 
the questionnaire in this study was found to be $r=0.744$ (see Table 2). Values above .7 are considered acceptable (Pallant, 2010).

Table 2: Cronbach's alpha for the Persian version of Metacognitive Awareness Inventory

\begin{tabular}{ll}
\hline Cronbach's Alpha & No of Items \\
\hline .744 & 52 \\
\hline
\end{tabular}

Students' level of pediatric nursing performance: Table 3 represents the mean and standard deviations of the learners' performance variable. The mean of total performance in the pediatric nursing was 4.9. The students' scores of lower and higher order questions were used to compute their score of total performance in the pediatric nursing. In oreder to compare the means of lower and higher order, these scores were converted to the same unit ranging from 0 to 10 . The mean of students' performance on lower order questions was found higher (mean=5.6550) compared to their performance on higher order questions (mean=4.1450). Table 3 provides details of the students' pediatric nursing performance.

Table 3: Students' Paediatric nursing performance

\begin{tabular}{llllll}
\hline & $\mathbf{N}$ & Minimum & Maximum & Mean & Std. Deviation \\
\hline Lower order questions & 40 & 2.50 & 8.70 & 5.6550 & 1.56647 \\
Higher order questions & 40 & 2.00 & 6.00 & 4.1450 & 1.36249 \\
Total performance & 40 & 2.50 & 7.00 & 4.9000 & 1.17833 \\
Valid N & 40 & & & & \\
\hline
\end{tabular}

Students' level of meta-cognitive strategy: Table 4 presents descriptive measures of the students' level of meta-cognition. The summative scores of the meta-cognitive strategy survey ranged from 52 and 260. The mean of the learners' level of overall meta-cognitive strategy was 2.95 (ratings measured were from one to five). The table provides a detailed list of the learners' level of each of the meta-cognitive strategy subscale. Findings provided a higher mean level of students' metacognitive strategy for knowledge of cognition subscale (3.0235) than the mean score for regulation of cognition subscale.

Table 4: Students' level of Meta-cognitive strategy

\begin{tabular}{llllll}
\hline & $\mathbf{N}$ & Minimum & Maximum & Mean & Std. Deviation \\
\hline Overall Meta-Cognition & 40 & 2.35 & 3.56 & 2.9500 & .30839 \\
Knowledge of Cognition & 40 & 2.24 & 3.71 & 3.0235 & .32922 \\
Regulation of Cognition & 40 & 2.00 & 3.66 & 2.9143 & .37755 \\
Valid N & 40 & & & & \\
\hline
\end{tabular}

Relationship between students' level of meta-cognitive awareness with pediatric nursing performance: Results from Table 5 showed that there was a significant positive and strong relationship between overall meta-cognitive strategy and pediatric nursing achievement and higher order performance with $r=.729$, sig=.000: $r=.831$, sig=.000, respectively. In addition, there was a significant positive and strong relationship between pediatric nursing performance and all the two subscales of meta-cognition (knowledge of cognition and regulation of cognition) with $r=.500$, sig=.001; $r=.673$, sig=.000, respectively.

Table 5: Correlation Analysis

\begin{tabular}{lllll}
\hline & & $\begin{array}{c}\text { Knowledge } \\
\text { of Cognition }\end{array}$ & $\begin{array}{c}\text { Regulation of } \\
\text { Cognition }\end{array}$ & $\begin{array}{c}\text { Overall Meta- } \\
\text { Cognition }\end{array}$ \\
\hline Lower order questions & Pearson Correlation & .180 & $.372\left(^{*}\right)$ & $.369\left(^{*}\right)$ \\
& Sig. (2-tailed) & .267 & .018 & .019 \\
& $\mathrm{~N}$ & 40 & 40 & 40 \\
\multirow{2}{*}{ Higher order questions } & Pearson Correlation & $.646\left(^{* *}\right)$ & $.735\left(^{* *}\right)$ & $.831\left(^{* *}\right)$ \\
& Sig. (2-tailed) & .000 & .000 & .000 \\
\multirow{2}{*}{ Total scores } & $\mathrm{N}$ & 40 & 40 & 40 \\
& Pearson Correlation & $.500\left(^{* *}\right)$ & $.673\left(^{* *}\right)$ & $.729\left(^{* *}\right)$ \\
& Sig. (2-tailed) & .001 & .000 & .000 \\
& $\mathrm{~N}$ & 40 & 40 & 40 \\
\hline
\end{tabular}




\section{Conclusion and Recommendations}

Performance of nursing students who were educated by traditional strategies was often fairly poor in higher thinking level. This study attempted to identify whether the students' performance was related to metacognitive awareness. Findings indicated that there was a positive, strong and significant relationship between higher order questions' performance and pediatric nursing achievement and meta-cognitive strategies and its subscales. As such, the researcher is of the opinion that some new strategies must be developed that can equip the students with higher level thinking skills and enable them to make a correct decision in new situations based on their knowledge.

\section{References}

Abdolhossini, A. (2012). The Effects of Cognitive and Meta-Cognitive Methods of Teaching in Mathematics. Procedia - Social and Behavioral Sciences, 46(0), 5894-5899.

Babakhani, N. (2011). The effect of teaching the cognitive and meta-cognitive strategies (self-instruction procedure) on verbal math problem-solving performance of primary school students with verbal problem- solving difficulties. Procedia - Social and Behavioral Sciences, 15(0), 563-570.

Bastable, S. B. (2007). Nurse as educator: principles of teaching and learning for nursing practice (3rd ed), Jones \& Bartlett Publishers.

Bayat, S. \& Tarmizi, R. A. (2010). Assessing Cognitive and Metacognitive Strategies during Algebra Problem Solving Among University Students. Procedia-Social and Behavioral Sciences, 8, 403-410.

Bengtsson, M. \& Ohlsson, B. (2010). The nursing and medical students' motivation to attain knowledge. Nurse Educ Today, 30(2), 150-156.

Flavell, J. H. (1976). Metacognitive aspects of problem solving. In L. B. Resnick. Hillsdale NJ: Lawrence Erlbaum.

Flavell, J. H. (1979). Metacognition and cognitive monitoring: A new area of cognitive-developmental inquiry. American Psychologist, 34(10), 906-911.

Gay, L. R., Mills, G. E. \& Airasian, P. (2006). Educational research: Competencies for Analysis and Applications (8th ed). Ohio: Merrill.

Gillespie, M. \& McFetridge, B. (2006). Nurse education - the role of the nurse teacher. Journal of Clinical Nursing, 15(5), 639-644.

Goh, C. C. M. \& Hu, G. (2013). Exploring the relationship between metacognitive awareness and listening performance with questionnaire data. Language Awareness, 1(1), 1-20.

Gwee, M. C. E. (2009). Problem-Based Learning: A Strategic Learning System Design For The Education Of Healthcare

LoBiondo-Wood, G. \& Haber, J. (2006). Nursing Research: Methods and Critical Appraisal for EvidenceBased Practice (6th ed.). Missouri: Mosby Elsevier.

Maneesriwongul, W. \& Dixon, J. K. (2004). Instrument translation process: a methods review. Journal of Advanced Nursing, 48(2), 175-186.

Moore, K. D. (2005). Effective instructional strategies: from theory to practice: Sage Publications, Inc.

Pallant, J. (2010). SPSS Survival Manual: A Step by Step Guide to Data Analysis Using SPSS: McGraw-Hill Education.

Pintrich, P. R. (2002). The Role of Metacognitive Knowledge in Learning, Teaching, and Assessing. Theory into Practice, 41(4), 220.

Pressley, M. \& Ghatala, E. S. (1990). Self-regulated learning: Monitoring learnong from text. Educational Psychologist, 25, 19-23.

Schraw, G. (1998). Promoting general metacognitive awareness. Instructional Science, 26(1-2), 113-125.

Schraw, G. \& Dennison, R. S. (1994). Assessing Metacognitive Awareness. Contemporary Educational Psychology, 19(4), 460-475.

Schraw, G. \& Moshman, D. (1995). Metacognitive theories. Educational psychology review, 7(4), 351-372.

Swanson, H. L. (1990). Influence of metacognitive knowledge and aptitude on problem solving. Journal of Educational Psychology, 82(2), 306-314.

Valcke, M. (2002). Cognitive load: updating the theory? Learning and Instruction, 12(1), 147-154. 